Journal of Applied Pharmaceutical Science Vol. 5 (03), pp. 019-023, March, 2015

Available online at http://www.japsonline.com

DOI: $10.7324 / \mathrm{JAPS} .2015 .50304$

ISSN 2231-3354 (cc) BY-NC-SA

\title{
Clarias batrachus collagen extract increases fibroblast cell adhesion, migration and proliferation
}

\author{
Lek Mun Leong ${ }^{\mathrm{a}}$, Ahmad Zorin Sahalan ${ }^{\mathrm{a}}$, Liew Huat Tan ${ }^{\mathrm{a}}$, Nor Hidayah Mustafa ${ }^{\mathrm{a}}$, Nor Fadilah Rajab ${ }^{\mathrm{a}, \mathrm{b} *}$ \\ ${ }^{a}$ Biomedical Science Programme, School of Diagnostic and Applied Health Science, Faculty of Health Sciences, Universiti Kebangsaan Malaysia, Jalan \\ Raja Muda Abdul Aziz, 50300 Kuala Lumpur, Malaysia. ${ }^{\text {b }}$ Toxicology Laboratory, Faculty of Health Sciences, Universiti Kebangsaan Malaysia, Jalan Raja \\ Muda Abdul Aziz, 50300 Kuala Lumpur, Malaysia.
}

\begin{tabular}{l} 
ARTICLE INFO \\
\hline Article history: \\
Received on: $21 / 11 / 2014$ \\
Revised on: 07/12/2014 \\
Accepted on: $29 / 01 / 2015$ \\
Available online: $28 / 03 / 2015$ \\
\hline Key words: \\
Clarias batrachus, collagen \\
extract, L929 cell, cell \\
migration.
\end{tabular}

\begin{abstract}
Collagen is an extracellular matrix protein with great importance in biomedical application. The search for collagen from various sources is intensified especially from marine source. This study was carried out to extract collagen from a Malaysian local fresh water fish, Clarias batrachus and characterized its biomedical potential In vitro. Collagen was extracted from C. batrachus skin using acetic acid method and identified using SDS-PAGE. MTT assay was performed to determine the effect of coated collagen on cell adhesion and proliferation of L929 skin fibroblast cells. Additionally, scratch assay was performed to examine the effect of collagen coating on fibroblast cell migration. Result showed that collagen extracted from $C$. batrachus was made up of collagen type I, which consists of two $\alpha$ chains ( $\alpha-1$ and $\alpha-2)$ and $\beta$ chain. At $100 \mu \mathrm{g} / \mathrm{cm}^{2}$ density, collagen coating significantly increased fibroblast cell adhesion, proliferation and migration compared to negative control $(p<0.05)$. As a conclusion, collagen extracted from $C$. batrachus increased cell adhesion, proliferation and migration of fibroblast cells and has potential to be used as an alternative source of collagen.
\end{abstract}

\section{INTRODUCTION}

Clarias batrachus, also known as ikan keli in Malay is a native species found predominantly in river of south-east Asia. $C$. batrachus is a type of fresh water fish inhabiting fresh water, brackish water, muddy marshes, as well as stagnant water (Emenike et al., 2012; Saha et al., 2011). These strong adaptive feature of $C$. batrachus is contributed by its ability to resist against various environmental challenges such as hypoxic, high environmental ammonia and desiccation stress (Saha et al., 2011). C. batrachus had been an important food source for Asian due to its abundance presence. It has high market demand due to its taste and medicinal properties thus making it important in aquaculture industry in Malaysia (Khedkar et al., 2014; Tham et al., 2009). Intense research activity had been performed to develop the potential of $C$. batrachus as biomarker for insecticide, fertilizer and leachate pollution (Emenike et al.,

\footnotetext{
* Corresponding Author

Email:nfadilah@ukm.edu.my

Phone: +603-92897002
}

2012; Parveen et al., 2004; Tham et al., 2009). However, to date there are no studies to investigate the potential of collagen extract from $C$. batrachus. Collagen is well known protein that had wide application in medical field as drug delivery system and tissue engineering (Lee et al., 2001). Collagen also served as matrix to transport cytokine, drug and even cultured skin cells to wound (Hart et al., 2002; Lee et al., 2001; Ravari et al., 2011; Varga et al., 2014).

There were studies done to develop collagen for diabetic lesion application (Chikazu et al., 2010; Yan et al., 2010). The wide application of collagen was contributed by the fact that collagen is a good surface active agent, exhibit good biodegradability and weak antigenicity (Lee et al., 2001). Amongst various type of collagen, type 1 collagen which attributed up to $90 \%$ of collagen presence in human body had been extensively used for biomedical application (Pati et al., 2012). A wound is a disrupt in the epithelial integrity of skin and may be accompanied by disruption of structure and function of underlying normal tissue (Enoch \& Leaper 2008). Acute wound heals in four stage, namely hemostasis, inflammation, proliferation and remodeling (Williamson \& Harding 2004). 
Efforts were spent to develop collagen as scaffold to aid in wound healing, facilitate cytokine transportation to reduce inflammation and promote proliferation stage, in hope to speed up healing process (Enoch \& Leaper 2008; Hart et al., 2002; Ravari et al., 2011; Varga et al., 2014; Williamson \& Harding 2004; Yan et al., 2010). Commonly, collagen used in medical field was extracted from bovine source (Pati et al., 2012). However, there are growing concern of transmissible diseases, especially mad cow disease, ovine and caprine scrapie and other zoonoses for collagen product from bovine source (Pati et al., 2012). Hence, there are urges to develop alternative source of collagen. In this study, our team extracted collagen from $C$. batrachus and investigated collagen's adhesion, proliferation and migration role on fibroblast model by using L929 cell line. With the advancement of this study, we are seeking to develop a cheaper and readily available fish collagen from local source.

\section{MATERIAL AND METHOD}

\section{Cells and cell culture}

L929 fibroblast cells derived from mouse's skin were obtained from American type culture collection (ATCC). L929 cells were cultured in EMEM supplemented with $10 \%$ fetal bovine serum and $1 \%$ penicillin streptomycin and maintained at $37{ }^{\circ} \mathrm{C}$ in $5 \% \mathrm{CO}_{2}$ atmosphere. Further maintenance and subculturing of cells were done according to ATCC guideline.

\section{Collagen extraction from $C$. batrachus skin}

Collagen extraction was adapted from Takeshi and Suzuki (2000) with slight modification (Takeshi \& Suzuki 2000) . C. Batrachus skin was cut into small pieces and rinsed in running distilled water. Fat was removed from skin using $10 \%$ butyl alcohol for 1 day at $4{ }^{\circ} \mathrm{C}$. The insoluble residue was filtered and rinsed with distilled water. Collagen was extracted from the residue with $0.5 \mathrm{M}$ acetic acid for 1 day at $4{ }^{\circ} \mathrm{C}$. Unwanted precipitate was filtered out with gauze before centrifuged at $4{ }^{\circ} \mathrm{C}$ with the speed 15000 r.p.m. Supernatant was obtained and added with $2 \mathrm{mg} / \mathrm{ml}$ pepsin with the ratio 9 portion of supernatant mixed with 1 portion of pepsin. Mixture was left to stand for 24 hours at $4{ }^{\circ} \mathrm{C}$ for enzymatic cleavage. The viscous solution was salted out thereafter by addition of $50 \% \mathrm{NaCl}$. Mixture was centrifuged and precipitate was obtained. Precipitate was suspended with $0.5 \mathrm{M}$ acetic acid and centrifuged to remove any impurities. The viscous collagen extract was freeze dried to remove water content. Dry weight yield was recorded. Total protein level was determined in collagen extract using Bradford Assay (Bradford 1976).

\section{SDS PAGE}

SDS PAGE was performed to estimate the molecular weight of collagen extracted. SDS PAGE protocol was adopted from Laemmli (1970) (Laemmli 1970). Briefly, collagen powder was dissolved in $0.1 \mathrm{M}$ acetic acid to a final concentration of 10 $\mathrm{mg} / \mathrm{ml}$. Collagen solution was mixed with $5 \mathrm{X}$ sample buffer in ratio of $4: 1$. Samples were denatured by heating to $95{ }^{\circ} \mathrm{C}$ in water bath for 5 minutes. $20 \mu \mathrm{l}$ of samples were then loaded into wells on top of $4 \%$ stacking gel and $10 \%$ resolving gel. Molecular weight protein marker (Biorad, USA) was loaded. Stacking were executed at $100 \mathrm{~V}$ for 10 minutes followed by resolving at $150 \mathrm{~V}$ for 60 minutes. The generated gel was stained with Coomasie brilliant blue dye $(0.25 \%$ Comassie blue R-250 in $15 \%$ methanol and $5 \%$ acetic acid) for 30 minutes and subsequently destained using destaining solution (10\% methanol mixed with $7.5 \%$ acetic acid) until clear background was obtained. Gel was dried and visualized under gel imaging software (Vilber Lourmat, USA).

\section{Collagen coating on plasticware}

Collagen powder was mixed with $0.1 \mathrm{M}$ acetic acid and stirred until dissolved. The collagen solution was then transferred to a sterile universal bottle. Chloroform was layered carefully at the bottom up to $10 \%$ of collagen solution volume. The bottle was allowed to stand overnight in cold. This step was performed to sterilize the collagen solution prior usage. The top layer containing collagen solution was then removed aseptically. 96 well plate and petri dishes were coated with collagen solution at the density 10 $\mu \mathrm{g} / \mathrm{cm}^{2}$ and $100 \mu \mathrm{g} / \mathrm{cm}^{2}$ respectively. Collagen was allowed to anchor on petri dish surface up to 4 hours at room temperature. Excessive solution was discarded and coated petri dishes were UV in a sterile tissue culture hood overnight to ensure sterility. Prior to usage, coated petri dish was rinsed with sterile PBS three times to remove any acetic acid residue.

\section{Cell adhesion assay}

$5 \times 10^{5}$ L929 cells were seeded in $60 \mathrm{~mm}$ petri dish coated with $C$. batrachus collagen as described above. At 1, 2, 4 and 6 hours respectively, liquid was withdrawn and phosphate buffered saline (PBS) was added to wash the cell in each plate lightly three times. The cells were trypsinized with $0.25 \%$ trypsin and counted. The cell adhesion ratio (AR) was calculated by the formula:

$$
\mathrm{AR}=\frac{\text { number of cells adhering to plate }}{\text { total cell number }} \times 100 \%
$$

\section{Cell proliferation assay}

MTT [3-(4,5-Dimethyl-2-thiazolyl)-2,5-diphenyl-2Htetrazolium bromide] assay was performed to determine potential proliferation effect of collagen on L929 cell line. MTT assay was performed as previously described (Mosmann 1983). Briefly, 96 well plates were coated with $10 \mu \mathrm{g} / \mathrm{cm}^{2}$ and $100 \mu \mathrm{g} / \mathrm{cm}^{2}$ collagen extract as mentioned above. $1 \times 10^{4}$ L929 cells were seeded in each well and allowed to be incubated for 72 hours. Culture dish served as negative control. After incubation time, MTT solution (5 $\mathrm{mg} / \mathrm{ml}$ ) (Sigma-Aldrich, USA) was added to plate at the final concentration of $0.5 \mathrm{mg} / \mathrm{ml}$ and allowed to incubate for 4 hours. Thereafter, supernatant was removed and DMSO was added to dissolve the formed formazon crystal. Plate was incubated for 15 minutes prior to measurement at $570 \mathrm{~nm}$ with ELISA plate reader (Biorad, USA). Proliferation rate induced by collagen was calculated following the below equation: 
$\%$ Proliferation $=\frac{\text { Optical density of sample }}{\text { Optical density of negative control }} \times 100 \%$

\section{In vitro scratch test}

Scratch test was performed with slight modification (Liang et al., 2007). Briefly, 5x10 5 sub-confluent cells were seeded in $60 \mathrm{~mm}$ petri dish coated with $10 \mu \mathrm{g} / \mathrm{cm}^{2}$ and $100 \mu \mathrm{g} / \mathrm{cm}^{2}$ collagen and allowed to grow until confluent monolayer was formed. The cell monolayer was scratched in a straight line with a p200 pipette tip. Cell monolayer was washed with $1 \mathrm{ml}$ of growth media and replaced with $5 \mathrm{ml}$ of media. Cells were incubated for 24 hours. After incubation, cells were washed once with PBS slowly to prevent cells from detached from surface. Then, cells were fixed with $3.7 \%$ paraformaldehyde for 30 minutes. Staining was then performed with $1 \%$ crystal violet for 30 minutes. Images were acquired for each sample using $Q$ Capture software. Images were analyzed quantitatively using Axio Vision software. Migration rate was compared between culture dish which served as negative control and collagen coated plate.

\section{Statistical analysis}

All experiments were carried out in triplicate and results were expressed as mean \pm standard error of mean for negative control and collagen treated groups, which were subjected to statistical comparison using student $\mathrm{t}$ test. Difference was considered significant at $p<0.05$.

\section{RESULT}

\section{Extraction yield}

$62.74 \mathrm{~g}$ of skin was used and $3.50 \mathrm{~g}$ of collagen dry weight was obtained. Collagen extracted using method from Nagai and Suzuki (2000) yield $5.58 \%$ of dry weight. There was $25.20 \%$ of protein available in the collagen extract obtained.

\section{C. batrachus collagen extract consisted primarily of collagen type I}

Subunit composition of collagen extract was examined by SDS-PAGE. Pattern of protein electrophoresis was shown in Figure 1. C. batrachus collagen was shown to comprise of $\alpha 1, \alpha 2$ and $\beta$ chains. The amount of $\alpha 2$ chain was relatively small compared to $\alpha 1$ and $\beta$ chains.

\section{C. batrachus collagen extract increased adhesion rate of fibroblast cell}

In order to investigate the effect of $C$. batrachus collagen on cell adhesion rate, adhesion test was carried out. Cells attached on collagen coated plate were compared to culture dish as negative control. Starting from 2 hours time point, the number of cells attached on $100 \mu \mathrm{g} / \mathrm{cm}^{2}$ collagen coated plate was significantly higher compared to negative control $(p<0.05)$. The percentage of cell adhesion is shown at Figure 2.

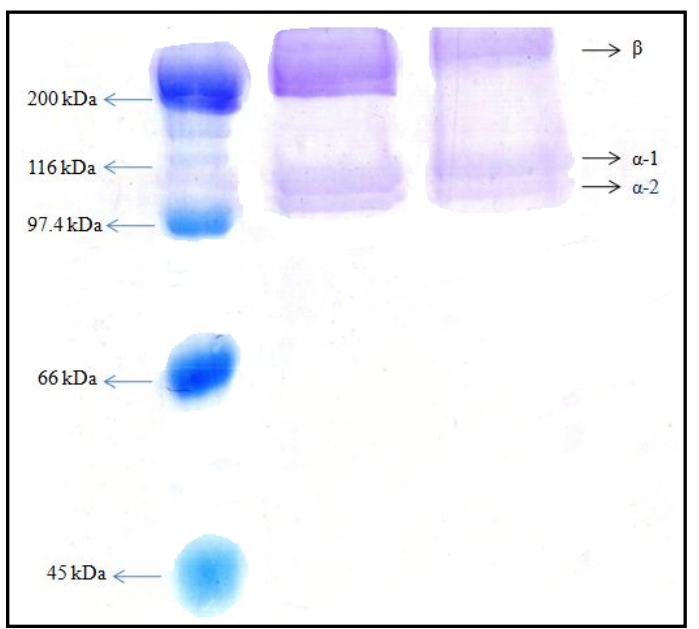

Fig. 1: SDS PAGE of calf collagen type 1 and $C$. batrachus collagen extract on $10 \%$ gel.

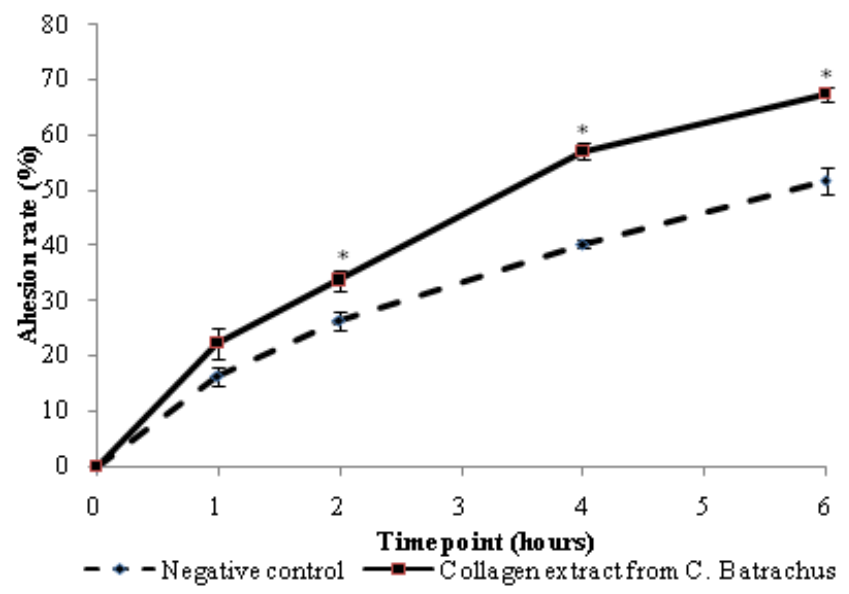

Fig. 2: Adhesion rate curve of L929 cultured on collagen coated plate. Data represent the mean of three independent experiments \pm SEM. $* \mathrm{p}<0.05$ compared to negative control

\section{C. batrachus collagen extract increased fibroblast cells proliferation}

MTT assay was performed in order to determine if collagen coating had any substantial effect on fibroblast cell viability or proliferation. Proliferation rate of cells grown on collagen coated plate was significantly higher $(p<0.05)$ than the proliferation rate of cells grown on culture dish. Collagen coating as low as $10 \mu \mathrm{g} / \mathrm{cm}^{2}$ improved proliferation rate of fibroblast significantly $(p<0.05)$ but increment of coating density to 100 $\mu \mathrm{g} / \mathrm{cm}^{2}$ does not improve proliferation rate substantially.

\section{C. batrachus collagen extract stimulated migration of L929 fibroblast cell}

In vitro scratch test was performed to investigate the potential effect of $C$. batrachus collagen on L929 fibroblast cell migration. Scratch test result revealed that there was significant increment of cell migration triggered by collagen coating as low as $10 \mu \mathrm{g} / \mathrm{cm}^{2}(p<0.05)$. 


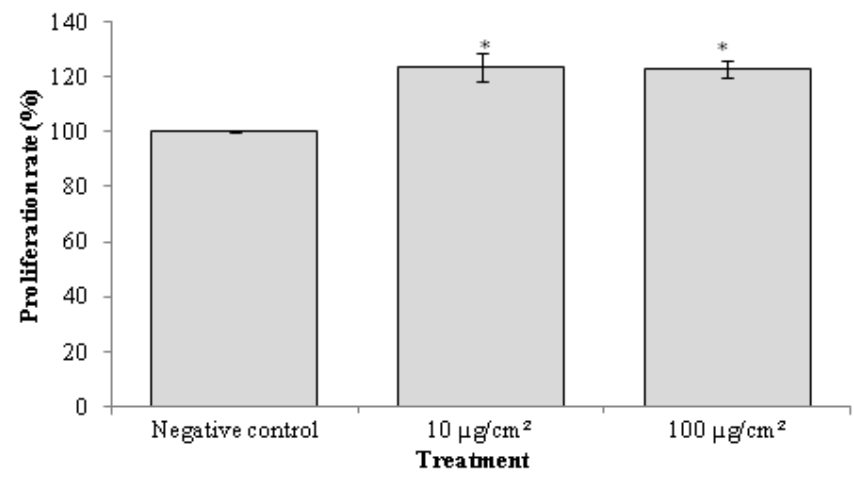

Figure 3 Proliferation rate of L929 fibroblast cell on various collagen extract coating density. Data represent the mean of three independent experiments \pm SEM. $* p<0.05$ compared to negative control
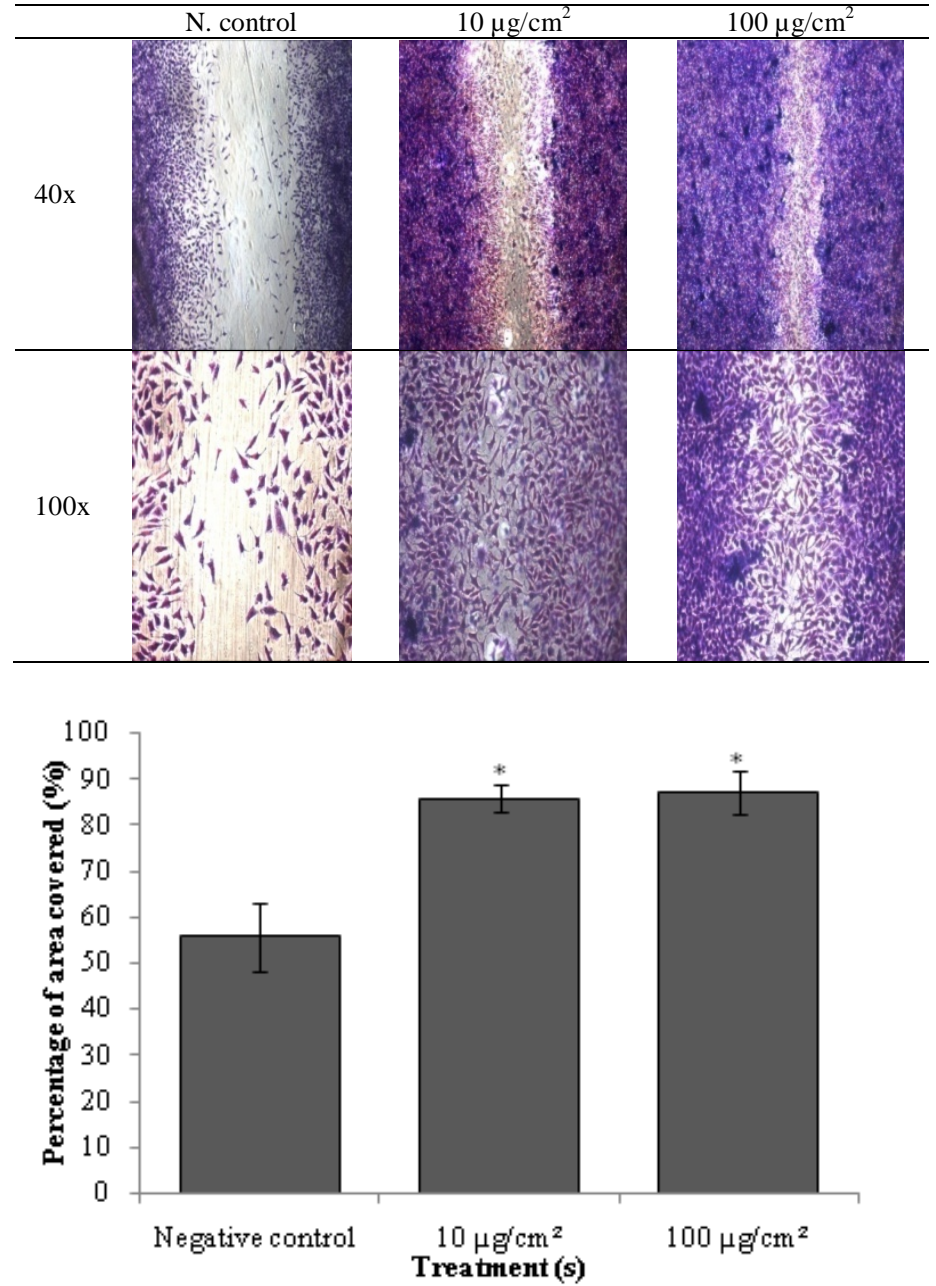

Fig. 4: Effect of collagen coating on L929 fibroblast cell migration during In vitro scratch test. Representative images show cells migrating into wounded area in scratch test. Data represent the mean of three independent experiments \pm SEM. $* p<0.05$ compared to negative control

\section{DISCUSSION}

Wound is a disruption of epithelial integrity on skin (Enoch \& Leaper 2008). Our body responses to wound through an intricate sequential physiological process that result in timely recovery (Anderson \& Hamm 2012). Delay in certain phase, for example inflammation and proliferation phase result in delayed wound healing (Anderson \& Hamm 2012).

Fibroblasts play an important role in proliferation stage of wound healing (Enoch \& Leaper 2008). The initiation of proliferation stage is characterized by migration of fibroblast into wound area (Enoch \& Leaper 2008). These fibroblasts have a role on synthesis, deposition and remodeling of extracellular matrix (ECM) (Williamson \& Harding 2004). Once inside wound area, fibroblasts will proliferate and start to produce matrix protein such as collagen and proteoglycan. These matrix proteins help to construct new extracellular matrix which supports further ingrowth of cells which is crucial for repair process (Enoch \& Leaper 2008). Fibroblasts migration and proliferation plays an important role in wound closure. Sufficient fibroblast proliferation leads to hasten ECM deposition and speed up recovery. Due to the importance of fibroblast in wound healing, skin derived fibroblast cell line, L929 was chosen as a model in this study.

Effort had been done to incorporate collagen into biomedical device to promote dermal fibroblast cell proliferation and migration in wound (Hart et al., 2002). It is found that such device is capable of speeding up wound closure in diabetic mice in vivo (Hart et al., 2002). Hart et al., (2002) demonstrated that ORC/collagen was a strong chemo attractant to dermal fibroblast. Our study further supported the finding from Hart et al., (2002) whereby $C$. batrachus was able to increase proliferation and migration of skin fibroblast In vitro. The mechanism behind $C$. batrachus ability to induce migration and proliferation is unclear and pending for exploration. However, type I collagen was shown to serve as chemo attractant for fibroblast In vitro (Postlethwaite et al., 1978). Study also revealed that smaller fractions of collagen such as $\alpha$ chain and smaller peptide digested from collagen also possess chemotactic properties. It is possible that regions of the collagen chains contains amino acid sequence which are capable of inducing fibroblast chemotaxis (Postlethwaite et al., 1978).

In this study, $C$. batrachus collagen was shown to improve adhesion of fibroblast significantly. Our finding was in agreement with Li et al.,, proving collagen superior adhesive properties for cells (Li et al., 2005). C. batrachus collagen's effect on the anchorage of fibroblast highlighted its potential to serve as scaffold. On the other hand, Pati et al., (2012) demonstrated that scaffold incorporated with fresh fish collagen improved cell proliferation rate. Our finding was parallel with Pati et al., findings. It is speculated that the presence of collagen improve the stability of cytoskeleton as well as activation of signal transduction leading to improvement in cell anchorage and proliferation under the influence of collagen (Han et al., 2011).

Biocompatibility of biomaterial is important aspect of safety before a biomaterial is introduced for human application. Biocompatibility of different fresh water fish collagen was studied previously (Pati et al., 2012). It was demonstrated collagen from fresh water fish explicit minimal inflammatory responses in vivo suggesting that fresh water fish collagen has high biocompatibility and potential to be developed as alternative source of collagen for scaffold (Pati et al., 2012). The biocompatibility of C. batrachus 
collagen remained to be studied before conclusion can be drawn. Taken together, this study leads to an evidence that $C$. batrachus collagen might potentially serves as a cheaper alternative source of collagen for biomedical application.

\section{CONCLUSION}

C. batrachus collagen extract increased cell adhesion, migration and proliferation of L929 fibroblast cells and has the potential to serve as alternative source of collagen for wound healing.

\section{CONFLICT OF INTEREST}

All authors declare no conflict of interest.

\section{ACKNOWLEDGEMENT}

We thank FRGS/1/2013/SKKO1/UKM/02/3 for financial support. We thank Centre of Research and Instrument Management (CRIM) for providing the gel documentation facility.

\section{REFERENCES}

Anderson, K \& Hamm, RL. Factors That Impair Wound Healing. Journal of the American College of Clinical Wound Specialists, 2012; 4(4):84-91.

Bradford, MM. A rapid and sensitive method for the quantitation of microgram quantities of protein utilizing the principle of protein-dye binding. Analytical Biochemistry, 1976; 72(1-2):248-254.

Chikazu, D, Taguchi, T, Koyama, H, Hikiji, H, Fujihara, H, Suenaga, H, Saijo, H, Mori, Y, Seto, I, Iino, M \& Takato, T. Improvement in wound healing by a novel synthetic collagen-gel dressing in genetically diabetic mice. Asian Journal of Oral and Maxillofacial Surgery, 2010; 22(2):61-67.

Emenike, CU, Fauziah, SH \& Agamuthu, P. Characterization and toxicological evaluation of leachate from closed sanitary landfill. Waste Management \& Research, 2012; 30(9):888-897.

Enoch, S \& Leaper, DJ. Basic science of wound healing. Surgery (Oxford), 2008; 26(2):31-37.

Han, SH, Uzawa, Y, Moriyama, T \& Kawamura, Y. Effect of collagen and collagen peptides from bluefin tuna abdominal skin on cancer cells. Health, 2011; 3(03):129-134.

Hart, J, Silcock, D, Gunnigle, S, Cullen, B, Light, ND \& Watt, PW. The role of oxidised regenerated cellulose/collagen in wound repair: effects In vitro on fibroblast biology and in vivo in a model of compromised healing. The International Journal of Biochemistry \& Cell Biology, 2002; 34(12):1557-1570.

Khedkar, GD, Tiknaik, A, Kalyankar, AD, Reddy A, CS., Khedkar, CD, Ron, TB \& Haymer, D. Genetic structure of populations and conservation issues relating to an endangered catfish, Clarias batrachus, in India. Mitochondrial DNA, 2014; 8:1-7.

Laemmli, UK. Cleavage of Structural Proteins during the Assembly of the Head of Bacteriophage T4. Nature, 1970; 227(5259):680685 .
Lee, $\mathrm{CH}$, Singla, A \& Lee, Y. Biomedical applications of collagen. International Journal of Pharmaceutics, 2001; 221(1-2):1-22.

Li, GY, Fukunaga, S, Takenouchi, K \& Nakamura, F. Comparative study of the physiological properties of collagen, gelatin and collagen hydrolysate as cosmetic materials. International Journal of Cosmetic Science, 2005; 27(2):101-106.

Liang, C-C, Park, AY \& Guan, J-L. In vitro scratch assay: a convenient and inexpensive method for analysis of cell migration In vitro. Nat. Protocols, 2007; 2(2):329-333.

Mosmann, T. Rapid colorimetric assay for cellular growth and survival: Application to proliferation and cytotoxicity assays. Journal of Immunological Methods, 1983; 65(1-2):55-63.

Parveen, M, Kumar, S \& Singh, P. Kinetic analysis of the in vivo inhibition of liver $\mathrm{AChE}$ in air breathing fish Clarias batrachus (Linnaeus, 1758). EUJ. Fish. Aqua. Sci, 2004; 21(1-2):143-144.

Pati, F, Datta, P, Adhikari, B, Dhara, S, Ghosh, K \& Mohapatra, PKD. Collagen scaffolds derived from fresh water fish origin and their biocompatibility. Journal of Biomedical Materials Research Part A, 2012; 100A(4):1068-1079.

Postlethwaite, AE, Seyer, JM \& Kang, AH. Chemotactic attraction of human fibroblasts to type I, II, and III collagens and collagenderived peptides. Proceedings of the National Academy of Sciences, 1978; 75(2):871-875.

Ravari, H, Hamidi-Almadari, D, Salimifar, M, Bonakdaran, S, Parizadeh, MR \& Koliakos, G. Treatment of non-healing wounds with autologous bone marrow cells, platelets, fibrin glue and collagen matrix. Cytotherapy, 2011; 13(6):705-711.

Saha, N, Jyrwa, L, Das, M \& Biswas, K. Influence of increased environmental water salinity on gluconeogenesis in the air-breathing walking catfish, Clarias batrachus. Fish Physiology and Biochemistry, 2011; 37(3):681-692.

Takeshi Nagai and Nobutaka Suzuki. Isolation of collagen from fish waste material skin, bone and fins. Food Chemistry, 2000; 68(3):277281.

Tham, L, Perumal, N, Syed, M, Shamaan, NA \& Shukor, M. Assessment of Clarias batrachus as a source of acetylcholinesterase (AChE) for the detection of insecticides. 2009; 30(1): 135-138.

Varga, M, Sixta, B, Bem, R, Matia, I, Jirkovska, A \& Adamec, M. Application of gentamicin-collagen sponge shortened wound healing time after minor amputations in diabetic patients-a prospective, randomised trial. Archives of Medical Science: AMS, 2014; 10(2):283287. 32(12):4-7

Williamson, D \& Harding, K. Wound healing. Medicine, 2004;

Yan, X, Chen, B, Lin, Y, Li, Y, Xiao, Z, Hou, X, Tan, Q \& Dai, J. Acceleration of diabetic wound healing by collagen-binding vascular endothelial growth factor in diabetic rat model. Diabetes Research and Clinical Practice, 2010; 90(1):66-72.

\section{How to cite this article:}

Lek Mun Leong, Ahmad Zorin Sahalan, Liew Huat Tan, Nor Hidayah Mustafa, Nor Fadilah Rajab. Clarias batrachus collagen extract increases fibroblast cell adhesion, migration and proliferation. J App Pharm Sci, 2015; 5 (03): 019-023. 